\title{
An Estimate of the Shadow Price of Water in the Southern Ogallala Aquifer
}

\author{
Ryan B. Williams ${ }^{1 *}$, Rashid Al-Hmoud2, Eduardo Segarra1', Donna Mitchell1 \\ ${ }^{1}$ Department of Agricultural and Applied Economics, Texas Tech University, Lubbock, TX., USA \\ ${ }^{2}$ Department of Economics and Geography, Texas Tech University, Lubbock, TX, USA \\ Email: *ryan.b.williams@ttu.edu
}

How to cite this paper: Williams, R.B., Al-Hmoud, R., Segarra, E. and Mitchell, D. (2017) An Estimate of the Shadow Price of Water in the Southern Ogallala Aquifer. Journal of Water Resource and Protection, 9, 289-304.

https://doi.org/10.4236/jwarp.2017.93019

Received: November 18, 2016

Accepted: February 25, 2017

Published: February 28, 2017

Copyright $\odot 2017$ by authors and Scientific Research Publishing Inc. This work is licensed under the Creative Commons Attribution International License (CC BY 4.0).

http://creativecommons.org/licenses/by/4.0/

\begin{abstract}
In this paper, we attempt to quantify the shadow price of an additional inch of groundwater resource left in situ for the Southern Ogallala Aquifer. Previous authors have shown the degree to which the optimal resource extraction path may diverge from the competitive extraction path based upon varying assumptions. We utilize high-quality data over an unconfined groundwater resource to evaluate the validity of these results. We find that the size of the existing groundwater resource is sufficiently small to result in a divergence between the competitive and socially optimal solutions. We are also able to confirm that the model responds to changes in the parameters in a manner consistent with previous research. Finally, we arrive at a marginal user cost for an additional acre-inch of water which is relatively low, but reasonable given uncertainty about future technological improvements.
\end{abstract}

\section{Keywords}

Groundwater, Resource Extraction, Hotelling Rule, Shadow Price

\section{Introduction}

The most dramatic externality imposed on society through the use of a nonrenewable resource is the loss of that resource for future uses. In the case of a finite aquifer, each individual producer faces the disappearance of access to the resource in subsequent producing periods as a result of their and their neighbors' pumping behavior. The greater the rate of withdrawals from the existing stocks in each period, the greater the rate at which the resource is depleted. The scarcity of the resource in such a situation leads to an opportunity cost for each unit of water that is extracted and utilized in the current period. The present value of these opportunity costs is the marginal user cost (MUC).

The southern portion of the Ogallala aquifer, which is contained primarily in 
the northwest portion of the State of Texas and the far eastern counties of New Mexico, is essentially a nonrenewable water resource. There exists almost no natural recharge into this portion of the aquifer, so it is like a "bathtub" of water which, when drained, will remain empty. Given the finite nature of the resource, every unit of water used has a potentially large opportunity cost.

The concept of optimal resource extraction is most notably presented by the seminal work of [1]. Maximizing a value function representing the future stream of net benefits to producers subject to the constraint of a finite resource, we arrive at the Hotelling rule for optimal resource extraction. This "rule" states that the percentage change in the current-value shadow price of the resource between each period should equal the discount rate if the resource is to be extracted optimally. The current-value shadow price is the difference between the price of the resource and the marginal extraction cost. The optimal extraction rate thus ensures that every unit of resource extracted yields the greatest possible value through time. [2] demonstrated the way in which these valuations might be made with specific groundwater data.

Many efforts have been made to determine the rate at which the Ogallala aquifer will decline under various assumptions. Most investigations have focused on the impact of water policy on conservation of the resource. Here we are interested in determining the social cost associated with extracting an additional unit of the resource beyond the socially efficient level. Such a valuation would serve to further inform water policy in the study region.

In addition to arriving at a shadow price for the remaining water in the aquifer, we wish to evaluate the divergence between the optimal extraction path and the competitive path. [3] found that as the size of the water resource increased the difference between the socially optimal extraction path and the extraction path under competition diminishes. Others (see for example [4]) have evaluated the robustness of the Gisser-Sanchez (G-S) result and found that there are numerous factors which lead to a divergence between the competitive result and the social optimum. The availability of high-quality data allows us to investigate these theoretical findings in the case of the Ogallala aquifer.

The purpose of this research is twofold. First, we wish to arrive at an estimate of the shadow price of additional units of water remaining in situ in the Ogallala aquifer. Second, we will compare the socially optimal result for water extraction with the competitive result in an effort to provide a comparison to the G-S result. In Section 2, we will provide a development of the model used to arrive at the shadow price. Section 3 will present the general and specific data used in this study. In Section 4, we will present the results of the study and discuss their meaning, as well as suggest future directions for research.

\section{The Model}

To evaluate the marginal user cost associated with the optimal extraction path for the producing region the basic model presented [3] and [4] is used. The optimal control assumption is that the central planner wishes to maximize the pre- 
sent value of the future profit streams of the agriculture producers in the region. To accomplish this, it is first necessary to understand the way in which currentperiod withdrawals affect the stock of the resource. The equation defining the motion of the hydrologic state is defined as:

$$
\dot{h} * A S=R+(\alpha-1) * w(t)
$$

where $\dot{h}$ is change in the saturated thickness of the aquifer between time periods, $A S$ is the area of the aquifer in acres times it's specific yield, $R$ is the rate of natural recharge to the aquifer, $\alpha$ is the return-flow coefficient, and $w(t)$ is the total volume of water withdrawals in acre-feet.

The saturated thickness of the aquifer measures the thickness of the aquifer, in feet, containing water. As water is withdrawn from the aquifer the saturated thickness will decline for an unconfined aquifer. The specific yield of the aquifer is the percentage of a unit of space in the aquifer that is comprised of the water resource. Multiplying $\dot{h}$ by $A S$ yields the total volume of water resource which exists in the aquifer at a given point in time. Therefore, the left hand side of Equation (1) is the change in the stock of the resource in the aquifer between two time periods. This change is a function of the volume of water that is taken out, in the form of water withdrawals for the purpose of irrigation, and water returning to the aquifer. The water returned to the aquifer takes two forms. The first is in the form of natural recharge. Recharge can occur as a result of deep percolation of surface water, flows from other underground water resources, or other hydrological relationships. The second way in which water may be added to the aquifer is through return flow, or applied irrigation water which is not taken up by the roots of the crop and ultimately percolates back to the depth of the aquifer. The return-flow coefficient $\alpha$, captures the percentage of applied irrigation water which ultimately returns to the aquifer.

To determine the stream of profits to the producer the revenues and costs of the typical producer are derived. [3] defines producer revenues as the area under the inverse demand curve for irrigation water. Therefore, the demand for irrigation water is given as:

$$
w=g+k P_{w}
$$

with $k<0 . P_{w}$ is the price of water, $w$ is the quantity of water demanded, and the parameters $g$ and $k$ are the intercept and slope values, respectively, of the water demand function. Solving the above equation for $P_{w}$ yields the inverse demand for irrigation water:

$$
P_{w}=\frac{1}{k} w-\frac{g}{k}
$$

[3], however, had available estimates for the parameters in the water demand function from local observations specifically related to their study. Because such estimates are not available for the current study, and due to the desire to account for the way in which water demand likely varies over crop and location, a specific demand for water is obtained for each crop in each county.

The inverse demand for water is derived from the following relationship:

$$
P_{w}=V M P_{w}=P_{y} * F^{t}(w) .
$$


Namely, the inverse demand for a given input to the production process should be equal to the value of the marginal product $(V M P)$. Producers will only employ an input (ceteris paribus) up to the point where its price is just equal to the additional value derived by employing an additional unit of input.

In order to obtain the marginal product of water $\left(M P_{w}\right)$, production functions for each crop in each county are used. Let the production function for crop $j$ in county $i$ be defined as:

$$
F_{i j}(w)=\alpha_{i j}+\beta_{i j} w-\gamma_{i j} w^{2}
$$

with $\alpha_{i j}, \beta_{i j}, \quad \gamma_{i j} \geq 0 \forall i, j$. The intercept term, $\alpha$, represents the yield associated with noapplied water. It is also worth noting that the production function is being restricted to water inputs without allowing for substitution between or augmentation by, other inputs. While there may be something to be gained by doing so, [5] found that the partial cross-price elasticities between water and other inputs (fertilizer, labor, energy, etc.) in cotton production in the United States were all statistically insignificant. Cotton production accounts for the majority of acreage in the study area, and we assume that the partial elasticities for the other crops are similar. The $M P_{w}$ is then simply $\frac{\partial F}{\partial w}$, or

$$
F_{i j}^{t}(w)=\beta_{i j}-2 \gamma_{i j} w .
$$

Combining the above relationship with Equation (3) yields the following:

$$
P_{y} * F_{i j}^{t}(w)=\frac{1}{k_{i j}} w-\frac{g_{i j}}{k_{i j}}
$$

where $P_{y} * F^{t}(t)$ is the $V M P_{w}$, and the right hand side of the equation is the inverse demand as defined by [3].

Multiplying the $M P_{w}$ by the price of output $\left(P_{y}\right)$ gives the $V M P_{w}$ as (note that the subscripts for crop and county have been dropped here for a simplified presentation):

$$
P_{y} * F^{t}(w)=P_{y} \beta-2 P_{y} \gamma w \text {. }
$$

In order to be consistent with [3] for the purpose of comparing results, the parameters are defined from their inverse demand for water in terms of the $V M P_{w}$. To do this, first set Equation (8) equal to Equation (3):

$$
P_{y} \beta-2 P_{y} \gamma w=\frac{1}{k} w-\frac{g}{k} \text {. }
$$

Letting $\frac{1}{k}=-2 P_{y} \gamma \quad\left(\right.$ or $k=\frac{-1}{2 P_{y \gamma}}$ ), then $\frac{g}{k}=-P_{y} \beta$. Substituting for $k$ yields the result that $g=\frac{\beta}{2 \gamma}$.

Total revenues are then obtained by integrating from 0 to $w$ along the inverse demand:

$$
T R=\int_{0}^{w} P_{w} \mathrm{~d} w=\int_{0}^{w}\left(\frac{1}{k} w-\frac{g}{k}\right) \mathrm{d} w
$$

or

$$
T R=\frac{1}{2 k} w^{2}-\frac{g}{k} w
$$


The second component of the producer's benefit function is their costs. This paper uses the linear cost function as put forth by [3]:

$$
T C=\left(c_{0}+c_{1} h\right) w .
$$

where $c_{0}>0, c_{1}<0$, and $c_{1}^{t}(h)=0$, recalling that $h$ is the saturated thickness of the aquifer. The fact that $c_{1}$ is negative is a result of the inverse relationship between the saturated thickness and the pumping lift. Pumping lift is the vertical distance that the groundwater resource must be raised via mechanical means. As lift increases, the cost to apply a given volume of water increases. Thus, as saturated thickness declines, the cost of applying water must increase. Additionally, it is important to note that the additional cost of pumping groundwater doesn't increase as the lift increases (or $\frac{\partial c_{1}}{\partial h}=0$ ). Some authors have explored the impact of a nonlinear cost function on the optimal control problem (see for example, [4]), but given the mechanics of pumping water, the linear cost function is more accurate ${ }^{1}$.

It should also be noted that the above cost function does not include the fixed costs associated with the ownership of an irrigation system. These costs may have some impact on production decisions by individual producers, but because fixed costs are not a function of withdrawals or lift, they would play no role in the optimal control problem.

Given the revenue and cost functions faced by producers, the objective is to maximize the present value of net benefits for producers, which is constrained by the dynamics of the resource stock as a function of producer behavior. The problem may be formally stated as:

$$
\max \int_{0}^{T} d^{-r t}\left[\frac{1}{2 k} w(t)^{2}-\frac{g}{k} w(t)-\left(c_{0}+c_{1} h(t)\right) w(t)\right] \mathrm{d} t .
$$

Subject to:

$$
\dot{h}=\frac{1}{A S}\left[R+(\alpha-1) w_{t}\right]
$$

which is simply the hydrologic state, Equation (1), rewritten. To solve the optimal control problem, define the Hamiltonian as:

$$
\mathcal{H}=\mathrm{e}^{-r t}\left[\frac{1}{2 k} w^{2}-\frac{g}{k} w-\left(c_{0}+c_{1} h\right) w\right]+\lambda[R+(\alpha-1) w] / A S
$$

where $h_{0}=h(0)$ is the initial saturated thickness of the aquifer less 30 feet, and $h(t) \geq 0$ for all $t=1, \cdots, T$. The state equation $(\partial H / \partial \lambda)$, costate equation $(-\partial H / \partial h)$, and first order condition $(\partial H / \partial w)$ are, respectively:

$$
\begin{gathered}
\dot{h}=[R+(\alpha-1) w] / A S \\
\dot{\lambda}=c_{1} w \mathrm{e}^{-r t}
\end{gathered}
$$

\footnotetext{
${ }^{1}$ Water horsepower $=\mathrm{GPM} \times($ head $(\mathrm{ft}) / 3960)$. Total head $(\mathrm{ft})$ is calculated as the sum of the lift $(\mathrm{ft})$ and the pressurization of the system (each PSI is equivalent to about 2.31 feet of lift). Therefore, if pressurization of the system and pumping rate remain unchanged, water horsepower is a linear function of lift (personal communication with Thomas W. Dorn, Extension Educator-UNL, University of Nebraska-Lincoln Extension in Lancaster County).
} 


$$
\mathrm{e}^{-r t} \frac{1}{k} w-\frac{g}{k}-\left(c_{0}+c_{1} h\right)+\lambda \frac{g-1}{A S}=0 .
$$

With the transversality conditions:

$$
w(t) \geq 0, \lambda(T) \geq 0, w(t) \lambda(T)=0 .
$$

Solving Equation (18) for $\lambda$ yields the following:

$$
\lambda(t)=\frac{-A S}{\alpha-1} \frac{1}{k} w(t)-\frac{g}{k}-\left(c_{0}+c_{1} h(t)\right) \mathrm{e}^{-r t} .
$$

Differentiating Equation (20) with respect to $t$, substituting Equation (17) for $\dot{\lambda}$ and Equation (16) for $\dot{h}$, and rearrangingterms results in a system of two differential equations in two unknowns. By imposing the transversality condition that $\lambda(t) \rightarrow 0$ as $t \rightarrow \infty$ it is possible to obtain a unique solution for $h(t)$ and $w(t)$, thereby solving the optimal control system.

Let us now turn our attention back to Equation (20), the present-value shadow price of the water resource. First, note that $\lambda(t)$ is a function of $A S$. In this form, the present-value shadow price is for a foot of saturated thickness remaining over the entire area of the aquifer. To convert this to a value that is meaningful for agricultural production, divide both sides by AS to obtain a shadow price per acre-inch of water in situ. Second, the cost function is in terms of saturated thickness (which doesn't affect the optimal control solution) instead of lift. The actual cost to the producer ofirrigation depends on the lift, not the saturated thickness, so I change $h(t)$ to $L(t)^{2}$. Because costs are increasing in $L(t)$ (as opposed to decreasing in $h(t)$ ), and $c_{1}<0$, the cost function must become $\left(c_{0}-c_{1} L(t)\right)$. These changes yield the following equation for the marginal user cost for an acre-foot of water:

$$
\lambda_{f}(t)=\frac{1}{1-\alpha}\left[\frac{1}{k} w(t)-\frac{g}{k}-\left(c_{0}-c_{1} L(t)\right)\right] \mathrm{e}^{-r t} .
$$

From Equation (21) it can be seen that $\lambda_{f}(t) \geq 0$. This follows from the assumption that withdrawals from the aquifer will only be taken by producers as long as the net benefit of doing so at the margin is non-negative, or

$$
\left(\frac{1}{k} w-\frac{g}{k}-\left(c_{0}-c_{1} L(t-1)\right)\right) \geq 0 .
$$

We can also obtain from Equation (17) that the marginal user cost should be decreasing through time $(\dot{\lambda}<0)$ because $c_{1}<0$. This result may seem to suggest that the increased scarcity of the resource isn't being taken into consideration. But this is the present-value shadow price, and as we move through time the stream of foregone benefits that could have been derived from an additional unit of the resource in situ is necessarily declining. The current-value shadow price will serve to reflect the increasing scarcity as the stock of water remaining in the aquifer declines.

Define the current-value shadow price of the resource as $\mu(t)=\lambda(t) \mathrm{e}^{r t}$.

${ }^{2} L t(h)<0$ : The bottom of the aquifer is fixed, as is the agricultural production surface to which water must be pumped. The difference between these two points is the sum of $L(t)$ and $h(t)$. 
Given that the marginal user cost is positive, it follows that $\mu(t) \geq 0 \forall t$. The time path of the current-value shadow price, $\dot{u}$, is less easily signed [6].

$$
\dot{u}=r * \lambda \mathrm{e}^{r t}+\dot{\lambda} \mathrm{e}^{r t} .
$$

The first argument in the equation is simply $r \cdot \mu$, or the discount rate times the current-value shadow price, and is always positive. The second argument can be simplified by substituting the right hand side of Equation (17) for $\dot{\lambda}$, which yields $c_{1} w$. Because withdrawals are non-negative in all time periods, and we have defined $c_{1}$ as strictly negative, $\dot{\lambda} \mathrm{e}^{r t}<0$. Thus, the two elements of the time pathfor $\mu(t)$ are working in opposite directions. The relative magnitudes of these two factors, therefore, determine whether or not the current-value shadow price is increasing or decreasing through time.

\section{The Data}

In order to evaluate the optimal control results derived in the previous section it is necessary to set values for all of the parameters of the model. Values for the hydrologic state equation, and their sources, will be presented first, followed by the producer's net benefit function, focusing on both the production function and the cost function.

Beginning with the hydrologic state,

$$
\dot{h}_{i}=\left[R_{i}+\left(\alpha_{i}-1\right) w_{i}\right] / A S_{i} .
$$

The area of the aquifer for each county $\left(A_{i}\right)$ was obtained by using GIS data to evaluate the area of county $i$ in acres which was overlying the Ogallala aquifer. The specific yield, $S_{i}$, is obtained for each county by dividing the total water in storage by the average saturated thickness times the acreage of the aquifer ( $S_{i}=$ storage $\left./\left(h_{i} * A_{i}\right)\right)^{3}$. Previous researchers that have utilized the specific yield have often settled on a value of 0.15 for specific yield (see for example [4] [7] [8]), which appears to be an accurate average value for the area of study.

The saturated thickness, $h$, that is used in this model will actually be a value less than total average saturated thickness. It is believed that with current irrigation technologies that the bottom 30 feet of saturated thickness in the aquifer is not usable for irrigation purposes [9]. The water contained within this portion of the aquifer would be too high in salinity to be applied to crops. Therefore, $h$ will be total average saturated thickness less 30 feet for all counties. The initial saturated thickness and lift data will reflect year 2004 values. A summary of these hydrologic parameters are provided below in Table 1.

The remaining parameters, $R$ and $\alpha$ constitute the total recharge to the aquifer. The return-flow coefficient, $\alpha$ depends on the soil profile in the study area as well as the irrigation technology being utilized. For the purpose of this study we assume that the representative producer is irrigating with LEPA (Low Energy Precision Application). Because LEPA is such an efficient irrigation technology (95 - 98 percent efficient [10]), there should be very little return-flow. [4] suggests that the

${ }^{3}$ Water storage and average saturated thickness values obtained from the Texas Tech Center for Geospatial Technology webpage: http://www.gis.ttu.edu/center. 
Table 1. Hydrologic parameters by county (acre-inches per year).

\begin{tabular}{cccccc}
\hline County & $\begin{array}{c}\text { Initial Usable Saturated } \\
\text { Thickness }\end{array}$ & Initial Lift & Acres & Specific Yield & $\mathrm{A}^{\star} \mathrm{S}$ \\
\hline Armstrong & 51 & - & 408052 & 0.119 & 48563 \\
Bailey & 32 & 108.01 & 513562 & 0.168 & 86030 \\
Castro & 55 & 240.12 & 585440 & 0.164 & 96264 \\
Cochran & 4 & 161.90 & 502039 & 0.151 & 75568 \\
Crosby & 71 & 237.00 & 451776 & 0.121 & 54642 \\
Deaf Smith & 29 & 211.91 & 884166 & 0.163 & 144501 \\
Floyd & 46 & 226.00 & 581810 & 0.152 & 88611 \\
Hale & 45 & 205.67 & 626719 & 0.162 & 101599 \\
Hockley & 10 & 126.66 & 588587 & 0.148 & 87351 \\
Lamb & 35 & 146.34 & 631566 & 0.163 & 102643 \\
Lubbock & 26 & 133.55 & 581265 & 0.151 & 87493 \\
Lynn & 7 & 51.43 & 565207 & 0.148 & 83725 \\
Parmer & 45 & 302.74 & 561555 & 0.165 & 92438 \\
Potter & - & - & - & - & - \\
Randall & 23 & 148.68 & 543271 & 0.150 & 81668 \\
Mean & 34.21 & 176.92 & 573215 & 0.152 & 87935 \\
\hline
\end{tabular}

return-flow coefficient could be as low as 0.005 for efficient technologies such as LEPA or SDI (subsurface drip irrigation). Because the representative producer doesn't account for all irrigation technologies, $\alpha$ is set to 0.01 .

Natural recharge, $R$, in the Southern portion of the Ogallala aquifer is largely unknown. There have been a multitude of studies conducted in order to determine an accurate value for recharge in this area, but those studies lead to results that vary from zero inches annually to greater than eight inches per year [7]. Because the natural recharge of the aquifer has been so difficult to pin down, and because it quite possibly varies significantly across the study area, the effects of allowing recharge to vary from 0 to $8 \mathrm{in} / \mathrm{yr}$ on the results will be evaluated. However, the majority of studies investigated by [7] find recharge rates between one-half and three inches annually, so a baseline recharge rate of one and onehalf inches per year will be set.

The parameters used for the producer's benefit function can be separated into two parts: Total revenues and the cost function. Total revenues are calculated by multiplying the price of output by the marginal product of water. Output prices are Marketing Year Average prices, and were obtained from the USDA NASS Agricultural Prices Annual Summaries (1999-2008), with the exception of the price for cotton, which was below the marketing loan price. Prices used are the average over the 10-year period of 1997-2006. This date range for prices was selected because it corresponds with other data used in this model-in particular the crop production functions. Due to the fact that relative commodity prices have not changed much, we feel that the use of this historical data is justified. The average commodity prices converted to year 2000 dollars per pound of commodity and are presented in Table 2. 
Table 2. Commodity prices (Year 2000 US \$).

\begin{tabular}{ccccccc}
\hline Year & Cotton $(\$)$ & $\begin{array}{c}\text { Corn } \\
(\$)\end{array}$ & Sorghum $(\$)$ & Wheat $(\$)$ & Soybean $(\$)$ & Peanut $(\$)$ \\
\hline 1997 & 0.5307 & 0.0432 & 0.0369 & 0.0478 & 0.0932 & 0.2146 \\
1998 & 0.5094 & 0.0366 & 0.0341 & 0.0403 & 0.0681 & 0.2234 \\
1999 & 0.3870 & 0.0349 & 0.0277 & 0.0359 & 0.0661 & 0.1945 \\
2000 & 0.4590 & 0.0389 & 0.0328 & 0.0420 & 0.0733 & 0.2460 \\
2001 & 0.2979 & 0.0429 & 0.0382 & 0.0486 & 0.0804 & 0.2371 \\
2002 & 0.4308 & 0.0494 & 0.0450 & 0.0542 & 0.0915 & 0.1960 \\
2003 & 0.6451 & 0.0517 & 0.0462 & 0.0570 & 0.1304 & 0.2180 \\
2004 & 0.4691 & 0.0542 & 0.0466 & 0.0650 & 0.1138 & 0.2241 \\
2005 & 0.5712 & 0.0543 & 0.0479 & 0.0706 & 0.1118 & 0.2216 \\
2006 & 0.5991 & 0.0739 & 0.0678 & 0.0964 & 0.1165 & 0.2420 \\
Mean & 0.4899 & 0.0480 & 0.0423 & 0.0558 & 0.0945 & 0.2217 \\
\hline
\end{tabular}

The marginal product of water was calculated for each of the five commodities (cotton, corn, sorghum, wheat, and peanuts) in each of the 12 counties of the study area (Bailey, Castro, Cochran, Crosby, Deaf Smith, Floyd, Hale, Hockley, Lamb, Lubbock, Lynn, and Parmer). Estimates for the marginal product were obtained by differentiating the production function for each crop in each county with respect to applied water. The quadratic production function is defined as Yield $_{i j}=\alpha_{i j}+\beta_{i j} w-\gamma_{i j} w^{2}$, with the parameters $\alpha, \beta$, and $\gamma$ taken from [8] and [11]. The intercept term, $\alpha$, represents the rain-fed production yield, while $\beta$ and $\gamma$ were estimated with an intercept forced to the origin. This method produces estimates for the production function that accurately disaggregate yields related to precipitation from yields related to irrigation water. Parameter estimates did not exist for Castro, Deaf Smith, or Parmer counties. For these counties estimates from the most proximal counties have been used. The production functions have been held constant through time for this analysis, which may have a significant impact on the optimal control results. Future research should allow for innovation in the production function in order to investigate the degree to which this affects optimal resource extraction in the region.

The cost function parameters were obtained using the IRRIGCOST.xls calculator. Values were acquired based upon the assumption of a center-pivot LEPA irrigation system, operating with a natural gas powered pump. The system is assumed to operate over a quarter section (160 acres), with the length of the systems lateral being $1 / 4$ mile. This system requires a pressurization of 15 PSI. The price of natural gas is assumed to be $\$ 3.60$ per MCF, which is the average price for the years 1997-2004 in year 2000 dollars.

The cost of pumping one acre-inch of water under the above conditions, regardless of the distance that the water must be lifted, is $\$ 3.14\left(c_{0}=3.14\right)$. The additional cost of pumping water over an additional inch of lift is $\$ 0.007$, so that $c_{1}$ $=-0.007$. Not included in the cost function, but relevant if we wanted to consid- 
er whether or not an individual producer should continue irrigating, are annual fixed costs of owning the LEPA irrigation system of $\$ 11,683$.

The final parameter that must be set in order to calculate the results of the optimal control solution is irrigated acreage. Total irrigated acreage and crop shares of irrigated acreage were obtained from the USDA-NASS Quick Stats. ${ }^{4}$ Values were obtained for the year 2004 for the five commodities being evaluated across the 13 county study areas. For the purpose of this study we assume that all acreages are fixed, both in total acres irrigated and in the type of crop being produced.

\section{Results}

Before presenting the marginal user cost results, which is the desired outcome of this work, it is informative to investigate some of the trends that present themselves in this analysis. First, when comparing the withdrawals and saturated thickness (see Table 3 ) in a single county for the competitive and optimal control results, it can be seen that the stock resource lasts significantly longer under optimal control. This is to be expected as the competitive solution doesn't place value on having access to the resource in future time periods. This same relationship holds for all counties in the study area, as indicated in Table 4.

The wedge between the time path for withdrawals (and saturated thickness), decreases as we allow future periods to be discounted at a greater rate. For instance, if the discount rate is allowed to vary between the $3 \%$ that we have initially assumed, and a relatively large value of $10 \%$ ([3] use this value), we can see that the higher discount rate moves the control solution toward the competitive solution (see Table 5). However, the increased discount rate still does not lead to results approximating the competitive solution, suggesting that the G-S result is really that of a very special case.

Another interesting result of the model is related to the recharge rate. It was stated in the section defining the data to be used that the recharge rate was assumed to be 1.5 inches per acre of the aquifer per year, but that estimates range between 0 and 8 inches. When allowing the recharge rate to vary from 0 to 8 inches per year, as would be expected, greater rates of natural recharge are consistent with maintaining saturated thickness.

In order to interpret the marginal user cost, which is the ultimate goal of this paper, it is important that we recall a couple of things. First, it was shown previously that the value of the marginal user cost should be positive, because it is a function of the difference between the marginal value of water and the marginal cost of extracting a unit of water. Second, the marginal user cost should be decreasing through time because it is the present-value shadow price of the resource. Third, the current-value shadow price should also be positive, but whether it is increasing or decreasing depends upon the relative magnitudes of the marginal cost of pumping due to increased lift, total withdrawals, and the marginal user cost.

${ }^{4}$ https://www.nass.usda.gov 
Table 3. Crosby county withdrawals and saturated thickness: $(r=0.03, R=0.125 \mathrm{ft})$.

\begin{tabular}{|c|c|c|c|c|}
\hline \multicolumn{3}{|c|}{ Withdrawals (inches) } & \multicolumn{2}{|c|}{ Saturated Thickness (Feet) } \\
\hline $\mathrm{t}$ & Optimal Control & Competition & Optimal Control & Competition \\
\hline 1 & 18.05 & 18.33 & 68.68 & 67.87 \\
\hline 2 & 18.04 & 18.32 & 66.35 & 64.75 \\
\hline 3 & 18.04 & 18.30 & 64.03 & 61.62 \\
\hline 4 & 18.03 & 18.29 & 61.71 & 58.50 \\
\hline 5 & 18.03 & 18.27 & 59.39 & 55.39 \\
\hline 6 & 18.02 & 18.25 & 57.07 & 52.27 \\
\hline 7 & 18.01 & 18.24 & 54.76 & 49.16 \\
\hline 8 & 18.01 & 18.22 & 52.44 & 46.06 \\
\hline 9 & 18.00 & 18.21 & 50.13 & 42.95 \\
\hline 10 & 18.00 & 18.19 & 47.81 & 39.85 \\
\hline 11 & 17.99 & 18.17 & 45.50 & 36.75 \\
\hline 12 & 17.98 & 18.16 & 43.19 & 33.66 \\
\hline 13 & 17.98 & 18.14 & 40.88 & 30.56 \\
\hline 14 & 17.97 & 18.13 & 38.57 & 27.47 \\
\hline 15 & 17.97 & 18.11 & 36.26 & 24.39 \\
\hline 16 & 17.96 & 18.10 & 33.95 & 21.30 \\
\hline 17 & 17.95 & 18.08 & 31.65 & 18.22 \\
\hline 18 & 17.95 & 18.06 & 29.34 & 15.14 \\
\hline 19 & 17.94 & 18.05 & 27.04 & 12.07 \\
\hline 20 & 17.94 & 18.03 & 24.73 & 8.99 \\
\hline 21 & 17.93 & 18.02 & 22.43 & 5.93 \\
\hline 22 & 17.92 & 18.00 & 20.13 & 2.86 \\
\hline 23 & 17.92 & 0.00 & 17.83 & 0.00 \\
\hline 24 & 17.91 & 0.00 & 15.53 & 0.00 \\
\hline 25 & 17.91 & 0.00 & 13.24 & 0.00 \\
\hline 26 & 17.90 & 0.00 & 10.94 & 0.00 \\
\hline 27 & 17.89 & 0.00 & 8.65 & 0.00 \\
\hline 28 & 17.89 & 0.00 & 6.35 & 0.00 \\
\hline 29 & 17.88 & 0.00 & 4.06 & 0.00 \\
\hline 30 & 17.88 & 0.00 & 1.77 & 0.00 \\
\hline 31 & 17.87 & 0.00 & 0.00 & 0.00 \\
\hline
\end{tabular}

Table 4. Estimated time to aquifer exhaustion in years.

\begin{tabular}{ccc}
\hline & Years to Exhaustion & \\
\hline County & Optimal Control & Competition \\
Bailey & 97 & 33 \\
Castro & 19 & 15 \\
Cochran & 4 & 2 \\
Crosby & 31 & 22 \\
Deaf Smith & 48 & 22 \\
Floyd & 21 & 15 \\
Hale & 9 & 7 \\
Hockley & 7 & 4 \\
Lamb & 14 & 10 \\
Lubbock & 10 & 7 \\
Lynn & 14 & 5 \\
Parmer & 17 & 13 \\
\hline
\end{tabular}


Table 5. Crosby county saturated thickness varied by discount rate.

\begin{tabular}{|c|c|c|c|c|}
\hline \multirow[b]{2}{*}{$\mathrm{T}$ (years) } & \multicolumn{4}{|c|}{ Saturated Thickness (Feet) } \\
\hline & $1 \%$ & $3 \%$ & $10 \%$ & Competition \\
\hline 1 & 68.77 & 68.68 & 68.64 & 67.87 \\
\hline 2 & 66.55 & 66.35 & 66.28 & 64.75 \\
\hline 3 & 64.32 & 64.03 & 63.92 & 61.62 \\
\hline 4 & 62.10 & 61.71 & 61.56 & 58.50 \\
\hline 5 & 59.87 & 59.39 & 59.21 & 55.39 \\
\hline 6 & 57.65 & 57.07 & 56.85 & 52.27 \\
\hline 7 & 55.43 & 54.76 & 54.50 & 49.16 \\
\hline 8 & 53.21 & 52.44 & 52.15 & 46.06 \\
\hline 9 & 50.99 & 50.13 & 49.80 & 42.95 \\
\hline 10 & 48.77 & 47.81 & 47.44 & 39.85 \\
\hline 11 & 46.56 & 45.50 & 45.10 & 36.75 \\
\hline 12 & 44.34 & 43.19 & 42.75 & 33.66 \\
\hline 13 & 42.13 & 40.88 & 40.40 & 30.56 \\
\hline 14 & 39.91 & 38.57 & 38.06 & 27.47 \\
\hline 15 & 37.70 & 36.26 & 35.71 & 24.39 \\
\hline 16 & 35.49 & 33.95 & 33.37 & 21.30 \\
\hline 17 & 33.28 & 31.65 & 31.02 & 18.22 \\
\hline 18 & 31.07 & 29.34 & 28.68 & 15.14 \\
\hline 19 & 28.86 & 27.04 & 26.34 & 12.07 \\
\hline 20 & 26.65 & 24.73 & 24.00 & 8.99 \\
\hline 21 & 24.44 & 22.43 & 21.67 & 5.93 \\
\hline 22 & 22.24 & 20.13 & 19.33 & 2.86 \\
\hline 23 & 20.03 & 17.83 & 17.00 & 0.00 \\
\hline 24 & 17.83 & 15.53 & 14.66 & 0.00 \\
\hline 25 & 15.63 & 13.24 & 12.33 & 0.00 \\
\hline 26 & 13.42 & 10.94 & 10.00 & 0.00 \\
\hline 27 & 11.22 & 8.65 & 7.66 & 0.00 \\
\hline 28 & 9.02 & 6.35 & 5.34 & 0.00 \\
\hline 29 & 6.82 & 4.06 & 3.01 & 0.00 \\
\hline 30 & 4.63 & 1.77 & 0.68 & 0.00 \\
\hline 31 & 2.43 & 0.00 & 0.00 & 0.00 \\
\hline 32 & 0.23 & 0.00 & 0.00 & 0.00 \\
\hline
\end{tabular}

In Figure 1, we can see that the marginal user cost for Bailey County is positive and decreasing, as we would expect. Bailey County was selected due to its greater initial saturated thickness, but all other counties in the area display the same trend. However, it is interesting to note that the current-value shadow price is also decreasing (see Figure 2). Recall that the current-value shadow price is the present value of the Lagrange multiplier $\left(\lambda(t) \mathrm{e}^{r t}\right)$. This suggests that the magnitude of the cost of total withdrawals remains larger than the marginal user cost times the discount rate, which is counter to what would be expected. While it is possible for 


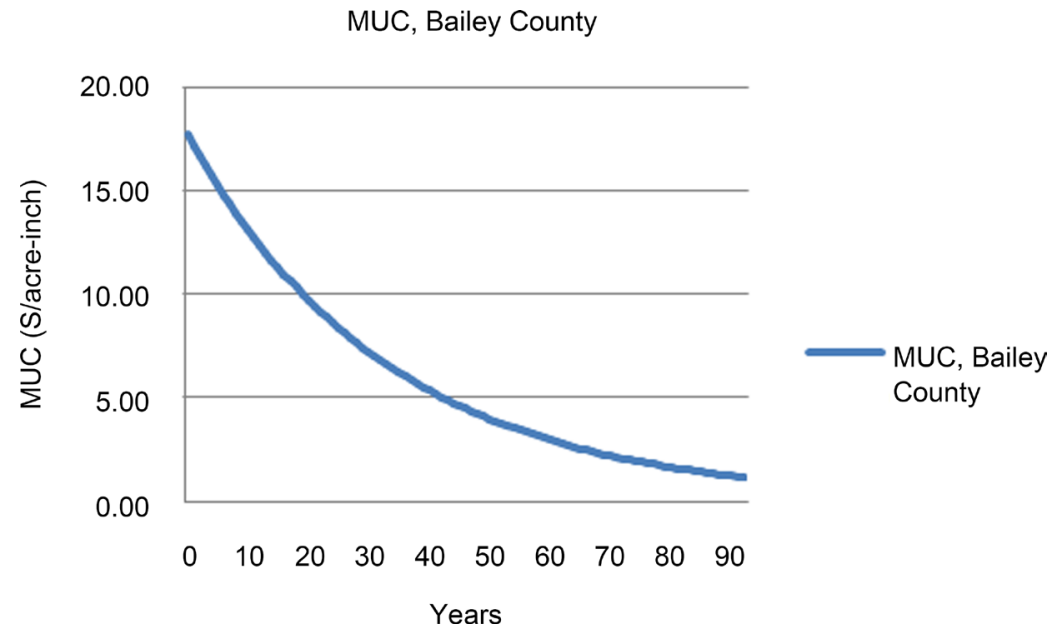

Figure 1. Bailey county marginal user cost.

Current-value shadow price, Bailey County
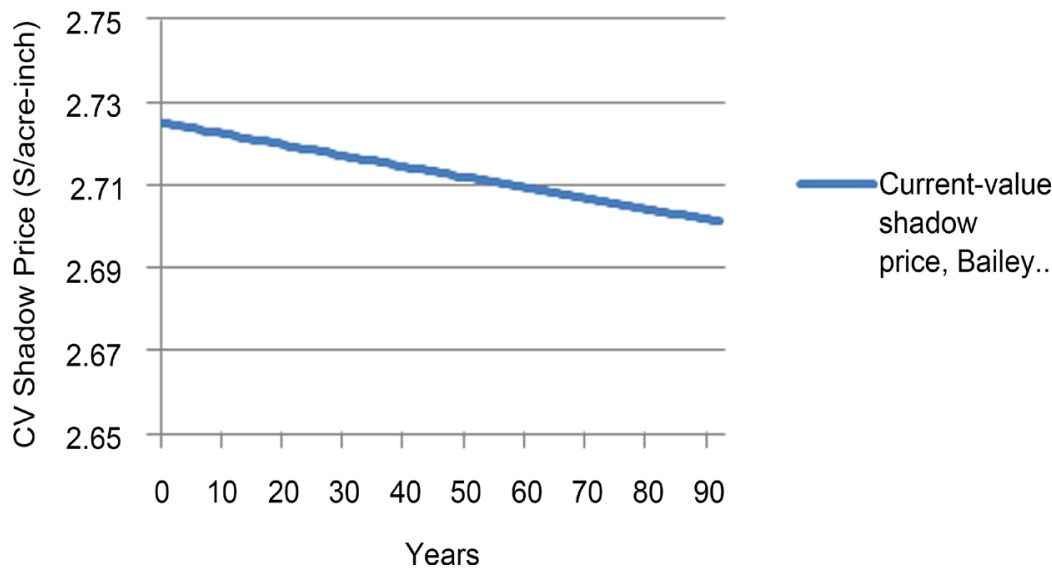
shadow price, Bailey...

Figure 2. Bailey county current-value shadow price.

the current-value shadow price to be increasing or decreasing over the life of a resource, it is expected that as the resource nears depletion that the increased scarcity would drive up this value. However, even in the counties where saturated thickness is only a couple of feet, this common result holds.

Next, we consider the marginal user cost as calculated here. There is great benefit in being able to place a baseline value on the social cost associated with additional application of water resources in terms of the stream of social benefit in future time periods. Presented in Table 6 is the marginal user cost calculated in the first time period across the 13 counties being examined.

It is first interesting to note that there is quite a bit of variability in these estimates. The marginal user cost varies from $\$ 0.60$ to $\$ 18.25$, with an average of $\$ 9.38$ for an additional acre-inch of water left in situ. If these values are compared to the value of an average acre-inch of water across the study region (calculated by multiplying (2000/specific water use) by price per pound, as presented in $\mathrm{Ta}$ ble 7), it appears that there is almost no value being placed on saving water for 
Table 6. Initial marginal user cost across study area.

\begin{tabular}{cccc}
\hline County & $\begin{array}{c}\text { Marginal User Cost } \\
\text { (\$/ac-in) }\end{array}$ & $\begin{array}{c}\text { Area of Aquifer (thousand } \\
\text { acres) }\end{array}$ & $\begin{array}{c}\text { Total County } \\
\text { MUC } \\
\text { (thousand \$inch) }\end{array}$ \\
\hline Bailey & 17.63 & 514 & 9053 \\
Castro & 12.77 & 585 & 7475 \\
Cochran & 11.59 & 502 & 5816 \\
Crosby & 0.60 & 452 & 269 \\
Deaf & 14.40 & 884 & 12734 \\
Smith & 6.80 & 582 & 3956 \\
Floyd & 12.38 & 627 & 7759 \\
Hale & 5.85 & 589 & 3443 \\
Hockley & 8.74 & 632 & 5519 \\
Lamb & 1.81 & 581 & 1052 \\
Lubbock & 1.74 & 565 & 984 \\
Lynn & 18.25 & 562 & 10247 \\
Parmer & 9.38 & 589 & 5692 \\
Mean & 6.10 & 106 & 3935 \\
St. Dev & & & \\
\hline & & 585 & \\
\hline
\end{tabular}

Table 7. Average value of acre-inch of water.

\begin{tabular}{ccccccc}
\hline Year & Cotton & Corn & Sorghum & Wheat & Soybean & Peanut \\
\hline 2004 & $\$ 20.71$ & $\$ 14.56$ & $\$ 7.19$ & $\$ 9.69$ & - & $\$ 33.24$ \\
\hline
\end{tabular}

production in future periods.

The second value worth noting is that over the entire study area, the social cost of an additional acre-inch of water being withdrawn from the aquifer is estimated to be $\$ 68,307,000$, with an average of $\$ 5,692,000$ per county. These values are concerning in that they suggest that the efficient use of the scarce resource is current withdrawals with no concern for future availability.

\section{Conclusions}

An analysis of data in the Texas Southern High Plains comparing an optimal control solution to a competitive solution regarding the extraction of the Ogallala Aquifer indicates an outcome contrary to the Gisser-Sanchez result. As the discount rate increases, the optimal solution converges to the competitive solution, but at a much slower rate, suggesting the storage capacity of the aquifer is relatively small.

Results showed an average marginal user cost of $\$ 9.38$ for an additional acreinch of water, meaning that very little value was placing on conserving water. When analyzing the current value shadow price, we see a result counter to what is expected. This is likely a result of two parts of the oversimplified model used here. First, holding output prices constant effectively holds the demand for water 
constant. If the value of water was rising through time as the water became scarcer, then we would likely see an increasing current-value shadow price. However, the price of water for agriculture isn't necessarily rising. As agricultural output increases dramatically around the world, the price of irrigation water may actually be falling (with the price of agricultural commodities). This, unfortunately, doesn't reflect the local scarcity of water.

Second, not allowing for irrigated acres to change in number or in commodity produced restricts the water resource from being utilized for its highest-valued use. A more advanced model that allows for a crop switching decision to be made would serve to clarify this possibility. Additionally, with fixed production function parameters, the model does not reflect the possibility of advancements in production technology. As long as innovation is restricted, the value of irrigation water in the future will be artificially low.

Additional research should be conducted before these values are used for policy purposes. It is worth recalling that the production functions and output prices are held constantly for this analysis. Increases in both the productive capabilities of a unit of irrigation water and output price would have the effect of increasing the demand for irrigation water. An increase in the demand would ultimately yield a higher price for water resources. Increases in the price of irrigation water in future periods of production would yield a higher opportunity cost for the current use of groundwater resources.

\section{Acknowledgements}

The research is supported in part by the Ogallala Aquifer Program, a consortium between USDA-Agricultural Research Service, Kansas State University, Texas AgriLife Research, Texas AgriLife Extension Service, Texas Tech University, and West Texas A \& M University.

\section{References}

[1] Hotelling, H. (1931) The Economics of Exhaustible Resources. The Journal of Political Economy, 39, 137-175. https://doi.org/10.1086/254195

[2] Burt, O.R. (1964) The Economics of Conjunctive Use of Ground and Surface Water. Hilgardia, 36, 31-111. https://doi.org/10.3733/hilg.v36n02p031

[3] Gisser, M. and Sanchez, D.A. (1980) Competition versus Optimal Control in Groundwater Pumping. Water Resources Research, 16, 638-642. https://doi.org/10.1029/WR016i004p00638

[4] Brill, T.C. and Burness, S. (1994) Planning versus Competitive Rates of Groundwater Pumping. Water Resources Research, 30, 1873-1880. https://doi.org/10.1029/94WR00535

[5] Uri, N.D. and Konyar, K. (1990) Energy Substitution in Cotton Production in the USA. International Journal of Energy Research, 14, 849-857. https://doi.org/10.1002/er.4440140807

[6] Caputo, M.R. (2005) Foundations of Dynamic Economic Analysis: Optimal Control Theory and Applications. Cambridge University Press, Cambridge. https://doi.org/10.1017/CBO9780511806827

[7] Mullican III, W.F., Johns, N.D. and Fryar, A.E. (1997) Playas and Recharge of the 
Ogallala Aquifer on the Southern High Plains of Texas-An Examination Using Numerical Techniques. Technical Report 242, Bureau of Economic Geology, the University of Texas at Austin, Austin.

[8] Wheeler, E.A. (2008) Water Conservation Reserve Program Alternatives for the Southern Ogallala Aquifer. PhD Thesis, Texas Tech University, Lubbock.

[9] Rawater, K. (2011) When Is the Aquifer Officially Depleted? National Ground Water Association, Westerville.

[10] Fipps, G. and Dainello, F.J. (2001) Irrigation. In: Dainello, F. and Cotner, S., Eds., Vegetable Growers' Handbook, Texas A\&M University, College Station, V1-V30.

[11] Wheeler, E.A. (2004) Policy Alternatives for the Ogallala Aquifer: Economic and Hydrologic Implications. Master's Thesis, Texas Tech University, Lubbock.

Submit or recommend next manuscript to SCIRP and we will provide best service for you:

Accepting pre-submission inquiries through Email, Facebook, LinkedIn, Twitter, etc. A wide selection of journals (inclusive of 9 subjects, more than 200 journals)

Providing 24-hour high-quality service

User-friendly online submission system

Fair and swift peer-review system

Efficient typesetting and proofreading procedure

Display of the result of downloads and visits, as well as the number of cited articles

Maximum dissemination of your research work

Submit your manuscript at: http://papersubmission.scirp.org/

Or contact jwarp@scirp.org 